\title{
Influence of Flaxseed on Lipid Profiles and Expression of LXR $\alpha$, in Intestine of Diabetic Rat
}

\author{
Abbas Mohammadi ${ }^{1,2}$, Fateme Mirzaei ${ }^{3}$, Mohammad Jamshidi $^{4}$, Reza Yari ${ }^{5}$, Solmaz Pak ${ }^{5}$, Parham Norouzian ${ }^{6}$, \\ Vahideh Abdolkarimi ${ }^{7} \&$ Ebrahim Abbasi Oshaghi ${ }^{4}$ \\ ${ }^{1}$ Department of Biochemistry, Afzalipour School of Medicine, Kerman University of Medical Sciences, Kerman, \\ Iran \\ ${ }^{2}$ Physiology Research Centre, Afzalipour School of Medicine, Kerman University of Medical Sciences, Kerman, \\ Iran \\ ${ }^{3}$ Department of Anatomy, Hamadan University of Medical Sciences, Hamadan, Iran \\ ${ }^{4}$ Department of Biochemistry, Medical School, Hamadan University of Medical Sciences, Hamadan, Iran \\ ${ }^{5}$ Department of Biology, Islamic Azad University, Boroūjerd Branch, Boroūjerd, Iran \\ ${ }^{6}$ Department of Pharmacy, Shiraz University of Medical Sciences International Branch, Shiraz, Iran \\ ${ }^{7}$ Tehran Daru Co, Tehran, Iran \\ Correspondence: Ebrahim Abbasi Oshaghi, Department of Biochemistry, Medical School, Hamadan University \\ of Medical Sciences, Hamadan, Iran. E-mail: 7abbasi@gmail.com
}

Received: June 17, 2013 Accepted: July 2, 2013 Online Published: September 3, 2013

doi:10.5539/ijb.v5n4p23 URL: http://dx.doi.org/10.5539/ijb.v5n4p23

\begin{abstract}
The aim of this study is to examine the effect of flaxseed on lipid profiles in diabetic rats, focusing on intestinal LXR $\alpha$. Animals were randomly divided into 3 groups of 8 rats each. group1: rats + chow diet (control), group 2: diabetic rats + chow diet (diabetic control), and group3: diabetic rats + chow diet $+4 \%$ flaxseed (w/w) (flaxseed group). After one-month rats were sacrificed, blood was collected; lipid profiles were determined enzymatically as well as mRNA and protein levels of SR-BI were determined by RT-PCR and westernblot respectively. Compared with diabetic control (group 2), total cholesterol (TC), low-density lipoprotein cholesterol (LDL-C), triglycerides, and very low density lipoprotein cholesterol (VLDL-C) (all of them $\mathrm{P}<0.01$ ) significantly decreased in flaxseed group (group 3). Intestinal LXR $\alpha$ mRNA was significantly increased $(\mathrm{P}<0.001)$ in flaxseed group treatment compared with diabetic animals (group 2). Levels of intestinal regulatory protein of LXR $\alpha$ significantly increased in flaxseed group $(\mathrm{P}<0.05)$. In conclusion, flaxseedsignificantly reduced TC, LDL-C, TG, VLDL-C and atherogenic index, as compared with the diabetic rats (group 2). On the other hand flaxseed led to up-regulation of LXR $\alpha$ in the intestine of rats.
\end{abstract}

Keyword: flaxseed, cholesterol, LXR $\alpha$, diabetes, Iran

\section{Introduction}

Dyslipidaemia is a major forecaster of cardiovascular disease (CVD) events and diabetic patient's mortality. High plasma concentration of total cholesterol and low-density lipoprotein (LDL) cholesterol are major risk factor for cardiovascular diseases (Vafa, 2012; Manhas, 2004).

Therefore, attentive control of lipid profiles is vital. Diabetic patient have two-four fold higher risk of developing coronary heart disease than people without diabetes, and CVDaccounts for 65-75 percent of diabetic patient deaths (Mohammed, 2010).

The restriction of nutritional cholesterol has been used as the principal primary therapeutic modality for the prevention and also treatment of dyslipidemia. Consequently, investigating nutritional components that can markedly improve dyslipidemia is important.

The livers $X$ receptors (LXR $\alpha$ and LXR $\beta$ ) are vital regulators of lipid and carbohydrate homeostasis that belong to the nuclear receptor superfamily. Two isotypes of LXR have been known in mammals including LXR $\alpha$ that is mainly expressed in the liver, intestine, spleen, kidney and adrenals, and LXR $\beta$ thatis expressed universally 
(Kruit, 2006).

LXR $\alpha$ by regulating of cholesterol transporters in the intestine plays important role in whole blood cholesterol. Flaxseed is recognized as a richest source of alpha-linolenic acid (ALA), lignans, phytoestrogen, and soluble fiber. Studies showed that flaxseed markedly reduced plasma cholesterol and suggested as a useful plant in prevention and treatment of cardiovascular disease (Pellizzon, 2007).

We have evaluated the hypolipidemic effects of flaxseed in diabetic rats. We also have measured expression of LXRain rat intestine.

\section{Method}

\subsection{Animals}

Male Wistar rats of same age with mean body weight of 200-250g were used for this experiment. The animals were bred and kept in the animal house. The animal house was maintained under standard hygienic condition, at a room temperature of $25 \pm 1{ }^{\circ} \mathrm{C}$ and relative humidity $55 \pm 5 \%$ with $12 \mathrm{~h} \mathrm{light/dark} \mathrm{cycle} \mathrm{(Hajianfar,} \mathrm{2013).}$ After one week of acclimation, rats were randomly divided into 3 groups of 8 rats each. Group 1: rats + chow diet (control), group2: diabetic rats + chow diet (diabetic control), and group3: diabetic rats + chow diet $+4 \%$ flaxseed (w/w) (flaxseed group). The procedure of this study has been approved by the Animal Research Ethic Committee of Tehran Payamenoor University (Tehran, Iran).

\subsection{Diabetic Rats}

After an overnight fast, diabetes was induced in animals by a single intraperitoneal (i.p.) injection of streptozotoc in $(70 \mathrm{mg} / \mathrm{kg}$ in $10 \mathrm{mM}$ citrate buffer, $\mathrm{pH} 4.5)$. Diabetes was recognized by polyuria, polydipsia and by evaluate of non-fasting serum glucose levels after one week. Rats with blood glucose levels greater than $300 \mathrm{mg} / \mathrm{dl}$ were considered diabetic (Abbasi-Oshaghi, 2012).

\subsection{Preparing Samples}

After one month, the rats were anesthetized with diethyl ether and killed by decapitation. Blood samples of each rat were collected by cardiac puncture into glass tubes and afterward centrifuged at $3000 \mathrm{rpm}$, for $15 \mathrm{~min}$ at $4{ }^{\circ} \mathrm{C}$. The serum was conveyed to a clean glass tube and stored at $-20{ }^{\circ} \mathrm{C}$ (Mohammadi, 2012; Esfahani, 2013).

\subsection{Biochemical Analysis}

Amount of TG, TC and HDL-C were measured enzematicaly using kits (Pars Azmoon, Iran). Levels of LDL-C and VLDL-C were calculated according to the Friedewald formula. Non-HDL-cholesterol concentration was calculated by subtracting HDL-C from total cholesterol (Ghamar-Chehreh, 2012).

\subsection{Semiquantitative $R T-P C R$}

RNA from intestine was extracted with Accuzol Reagent (Bioneer, Korea) according to the manufacturers' protocol. Synthesis of cDNA was performed according to the manufacturer's protocol (Fermentas, Lithuania). For semiquantitative RT-PCR reaction $13 \mu \mathrm{l}$ PCR Master Mix (Cinnagen, Iran), $1 \mu \mathrm{l}$ forward primer (P mol $/ \mu \mathrm{l}$ ), $1 \mu \mathrm{l}$ reverse primer $(\mathrm{P} \mathrm{mol} / \mu \mathrm{l}), 2 \mu \mathrm{cDNA}$ and $8 \mu \mathrm{l}$ deionized water were added into a sterile tube on ice, and centrifuged for a short time. Thirty five cycles of PCR amplification were achieved with denaturation at $95{ }^{\circ} \mathrm{C}$ for $30 \mathrm{~s}$, annealing at $63{ }^{\circ} \mathrm{C}$ for $30 \mathrm{~s}$, and extension at $72{ }^{\circ} \mathrm{C}$ for $30 \mathrm{~s}$ using a PCR machine. All reactions were completed with a single additional cycle at $72{ }^{\circ} \mathrm{C}$ for 5 minutes. The samples were electrophoresed on a $2 \%$ agarose gel and visualized by ethidium bromide staining. The primers that used in this studywere fallowing: $\beta$ actin : upper, 5'-TGG AAT CCT GTG GCA TCC ATG AAA C-3'lower primer, 5'-TAA AAC GCA GCT CAG TAA CAG TCC G-3' LXR alpha : pper primer, F: 5'-GCG TCC ATT CAG AGC AAG TGT-3', lower primer, 5'-TCA CTC GTG GAC ATC CCA GAT-3' (Mohammadi, 2012).

\subsection{Western Blotting}

About 50 mgofintestine samplewas homogenized in $500 \mu 1$ of RIPA buffer which containing $1 \%$ protein inhibitor cocktail (Santa Cruz, USA) and $1 \mu$ M PMSF. The homogenate then was centrifuged at 14,000 rpm for 15 min at $4{ }^{\circ} \mathrm{C}$. Fifty microgram of protein was separated on a $12.5 \%$ SDS-PAGE gel and transferred to a Polyvinylidenedifluoride (PVDF) membrane (Roche Applied Science). The PVDF membrane was blocked ( $2 \mathrm{hr}$ ) with 3\% non-fat dried milk in Tris-buffered saline with Tween 20 (TBS-T, Roche Applied Science) at room temperature. The membrane then was probed with rabbit anti-LXR alpha antibody (1:300 dilutions, Santa Cruz), and rabbit polyclonal $\beta$-actin antibody (1:2000 dilutions, Novus Biological) for $1.5 \mathrm{hr}$ at room temperature. After washing in TBS-T (three times, $15 \mathrm{~min}$ ), the blots were incubated for $1.5 \mathrm{hr}$ sat room temperature with a horseradish peroxidase-conjugated secondary antibody (1:10000, Roche Applied Science). The complexes of 
antibody and antigen were exposed to ECL western blotting detection reagents (Roche Applied Science) for $30 \mathrm{~s}$ and the film was developed. Lab Work analyzing software (UVP, UK) was used to analyze Band densities. Data are expressed as the percent ratio of the LXR to $\beta$-Actin (Abbasi-Oshaghi, 2012; Mohammadi, 2012; Chen, 2009).

\subsection{Statistical Analysis}

The data were analyzed using one-way analysis of variance with ANOVA followed by Tukey. Results were expressed as mean values $\pm \mathrm{SD}$. The differences between groups were considered significant when $P<0.05$.

\section{Results}

\subsection{Effect of Flaxseed Treatment on Blood Lipid Levels}

The effect of flaxseed treatment on the blood lipid profiles of the tested rat groups is given in Table 1. The levels of TG $(P<0.001)$, VLDL-C $(P<0.001)$, TC $(P<0.01)$ and LDL-C $(P<0.01)$ significantly reduced in the flaxseed treatment rats compared with diabetic control.

The high levels of TC, LDL-C and TG were brought down markedly after one month treatment period. A fall of $36 \%$ in TC, $63 \%$ in LDL-C and 55\% in TG was observed in flaxseed treated group and there was also an increase of $7 \%$ HDL-C in the treated group compared with diabetic control.

Table 1. Lipid profiles in different treatment groups

\begin{tabular}{llll}
\hline Biochemical factors & diabetic rat+ Flaxseed & diabetic rat ( diabetic control) & chow diet (Control) \\
\hline TC & $75.10 \pm 5.29^{\mathrm{b}}$ & $119.40 \pm 9.16$ & $71.15 \pm 4.03^{\mathrm{b}}$ \\
TG & $62.93 \pm 5.53^{\mathrm{c}}$ & $142.17 \pm 11.2$ & $164.35 \pm 6.82^{\mathrm{c}}$ \\
LDL-C & $17.15 \pm 2.06^{\mathrm{b}}$ & $45.89 \pm 2.04$ & $16.22 \pm 1.08^{\mathrm{b}}$ \\
HDL-C & $49.70 \pm 5.50$ & $45.81 \pm 5.31$ & $43.75 \pm 5.60$ \\
VLDL-C & $12.52 \pm 0.35^{\mathrm{c}}$ & $28.34 \pm 0.61$ & $13.08 \pm 0.45^{\mathrm{c}}$
\end{tabular}

TC: Total cholesterol, TG: Triglyceride, LDL-C: Low-density lipoprotein cholesterol, HDL-C: High-density lipoprotein cholesterol, VLDL-C: Very low-density lipoprotein Cholesterol, Data represent as mean \pm SD $(n=8)$. ${ }^{\mathrm{a}} P<0.05,{ }^{\mathrm{b}} P<0.01$ and ${ }^{\mathrm{c}} P<0.001$ Considered as significant compared with diabetic control (diabetic rats + chow diet).

\subsection{Protein and mRNA Levels}

Intestinal LXR $\alpha$ protein significantly increased in flaxseed treated group in comparison with diabetic rats $(P<$ 0.05) (Figure 1).

LXR $\alpha$ mRNA significantly increased $(P<0.05)$ in flaxseed group in comparison with diabetic rats $($ Figure 2$)$. 


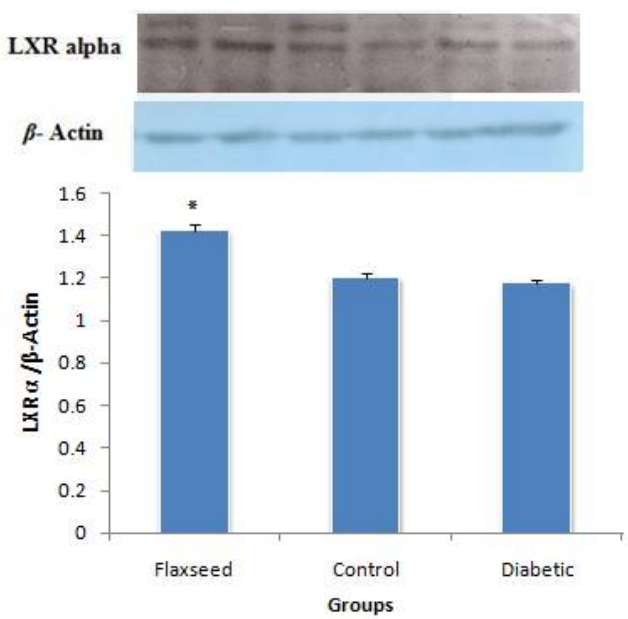

Figure 1. Expression of LXR protein in intestine of flaxseed, diabetic and control rats $(\mathrm{n}=8)$

LXR protein expression significantly increased in flaxseed group. ${ }^{*} p<0.05$ considered as significant compared with diabetic rats. Data are presented as means \pm SD. LXR alpha band from left to right; lane 1: flaxseed group (diabetic rats + chow diet $+4 \%$ flaxseed), 2 : control (rats + chow diet), 3: diabetic control (diabetic rats + chow ).

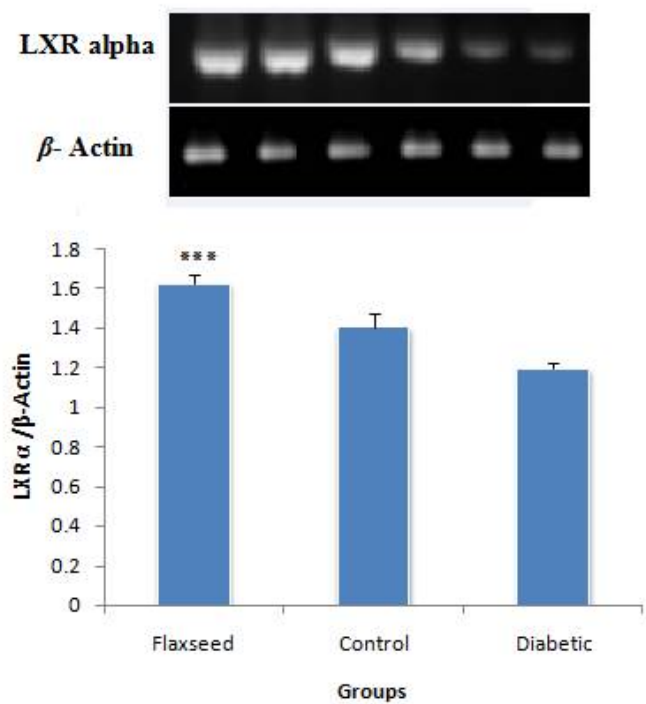

Figure 2. Expression of LXR mRNA in intestine of flaxseed, diabetic and control rats $(\mathrm{n}=8)$

LXR mRNA expression significantly increased in flaxseed group. ${ }^{* *} p<0.001$ considered as significant compared with diabetic rats. Data are presented as means \pm SD. LXR alpha band from left to right; lane 1: flaxseed group (diabetic rats + chow diet $+4 \%$ flaxseed), 2: control (rats + chow diet), 3: diabetic control (diabetic rats + chow ).

\section{Discussion}

\subsection{Biochemical Markers}

Prevalence of diabetes and cardiovascular disease are growing quickly in the world. Optimal control of lipid profiles in diabetic patient is very important to prevention of cardiovascular diseaseand also growing health is a matter in the world (Manhas, 2004). Diabetic patients frequently have higher total cholesterol, TG and LDL-C. 
This combination participates markedly to their cardiovascular risk.In the diabetic patients, and LDL-C is a powerful risk factor for cardiovascular (Brown, 2008).

In this study LDL-C significantly reduced by flaxseed. Studies have shown that rate of cardiovascular event is reduced by nearly $1 \%$ for every $1 \%$ decrease in LDL-C, and by at least $1 \%$ for every $1 \%$ raise in HDL-C (Brown, 2008).

We observed that the diabetic animals which fed flaxseed had the lowest plasma cholesterol concentration compared with the diabetic animals. However, high plasma cholesterol levels are related to coronary artery disease (CAD) (Manhas, 2004; Brown, 2008).

\subsection{Gene Expression}

Homeostasis of plasma cholesterol is controlled by a complex interaction of intestinal absorption, biliary clearance, faecal excretion and denovo synthesis. Absorption of cholesterol from intestinal has been established to be a main determinant of plasma lipid profiles.

Theliver X receptor (LXR) is a part of the nuclear receptor family of transcription factors liver X receptors (LXRs) are vital regulators of cholesterol, triglyceride, and glucose metabolism. Two isoforms of LXR have been recognized including $\mathrm{LXR} \alpha$ and $\mathrm{LXR} \beta$. LXR $\alpha$ expression is limited to liver, intestine, adipose tissue, kidney, lung, macrophages and spleen, while LXR $\beta$ is expressed in approximately all tissues. LXR $\alpha$ by regulating expression of many genes such as Niemann-Pick C1 Like 1 (NPC1L1) and heterodimer of ATPbinding cassette transporter G5 and G8 (ABCG5 andABCG8) leads to reduction of intestinal cholesterol absorption (Kruit, 2006; Zhoa \& Dahlman-Wright, 2010).

Activation of LXR increases both ABCG5 and ABCG8 expression, which transfer absorbed cholesterol back to the intestinal lumen. Studies have shown that administration of LXR agonists significantly decreases intestinal net cholesterol absorption in animals (Zhoa \& Dahlman-Wright, 2010).

NPC1L1 (Neimanna Pick C1 Like 1) has been recognized as a main cholesterol transporter which have important role in the cholesterol absorption. This protein is expressed in the brush border of enterocytes (Altmann, 2004). It was recently suggested that activation of LXR downregulates NPC1L1 expression.

Elevation of plasma cholesterol is related to atherosclerotic coronary heart disease. By reducing plasma cholesterol levels, NPC1L1 inhibition and activation of ABCG5 and ABCG8 should have useful effects on atherosclerosis (Davis, 2001). Treatment with flaxseed significantly reduces lowers total cholesterol probably with inhibition of cholesterol absorption, and also may inhibit the development and progression of atherosclerosis in diabetic rats.

Flaxseed is rich in alpha-linolenic acid (ALA), lignans, phytoestrogen, soluble fiber, and these substances are likely antioxidant and hypolipidemic effects. Thus, intake of flaxseed in diabetic rats enhanced antioxidant free radical scavenging capacity and significantly reduced lipid profiles. On the other hand, flaxseed with reduction of NPC1L1 and raise of ABCG5, ABCG8 and LXR $\alpha$ significantly reduced plasma LDL-C and total cholesterol. This research provides a rationale to examine these effects in diabetic patient.

\section{Acknowledgements}

We are thankful to Rezaii A, from Tehran Payeme Noor University for preparation of diabetic rats and safety of blood samples. We also would like to thanks professor Gholamhosseinian from Kerman Razi laboratory for analysis of biochemical factors and Borūjerd Azad University for gene expression help.

\section{References}

Abbasi-Oshaghi, E., Noori-Sorkhani, A., \& Rezaei, A. (2012). Effects of Walnut on Lipid Profile as Well as the Expression of Sterol-Regulatory Element Binding Protein-1c (SREBP-1c) and Peroxisome Proliferator Activated Receptors $\alpha(\mathrm{PPAR} \alpha)$ in Diabetic Rat. Food and Nutrition Sciences, 3(2), 255-259. http://dx.doi.org/10.4236/fns.2012.32037

Altmann, S. W., Davis, H.R., Zhu, L. J., Yao, X., Hoos, L. M., Tetzloff, G., ... Zeng, M. (2004). Niemann-Pick C1 Like 1 protein is critical for intestinal cholesterol absorption. Science, 303, 1201-1204. http://dx.doi.org/10.1126/science.1093131

Brown, W. V. (2008). Optimal management of lipids in diabetes and metabolic syndrome. Journal of Clinical Lipidology, 2, 335-342. http://dx.doi.org/10.1016/j.jacl.2008.08.444

Chen, Y., \& Chen, K. (2009). Characterization and Prokaryotic expression of Glucuronyltransferase-S Gene in Silkworm Bombyxmori. International Journal of Biology, 1(1), 104-109. 
Davis, J., Compton, H. R., Hoos, D. S., \& Tetzloff, G. (2001). Ezetimibe, a potent cholesterol absorption inhibitor, inhibits the development of atherosclerosis in ApoE knockout mice. Arterioscler Thromb Vasc Biol, 21, 2032-2038. http://dx.doi.org/10.1161/hq1201.100260

Esfahani, A. S., Gharakhanlou, R., Karimian, J., Khazaei, M., Feizi, A., \& Safarzade, A. (2013). Effect of Resistance Training on Plasma Nitric Oxide and Asymmetric Dimethylarginine Concentrations in Type I Diabetic Rats. Int J Prev Med, 4, 78-84.

Ghamar-Chehreh, M. E., Amini, M., Khedmat, H., Daraei, F., Mohtashami, R., \& Karbasi, A. (2012). Comparative Effectiveness of Ezetimibe in Improving Lipid Profile in Non-Alcoholic Fatty Liver Disease Patients: Statins Still Rule. International Journal of Biology, 4(2), 184-190. http://dx.doi.org/10.5539/ijb.v4n2p184

Hajianfar, H., Paknahad, Z., \& Bahonar, A. (2013). The Effect of Omega-3 Supplements on Antioxidant Capacity in Patients with Type 2 Diabetes. J Prev Med, 2, 234-238.

Kruit, J. K., Groen, A. K., Berkel, T. J., \& Kuipers, F. (2006). Emerging roles of the intestine in control of cholesterol metabolism. World J Gastroenterol, 12(40), 6429-6439.

Manhas, A., \& Farmer, J. A. (2004). Hypolipidemic therapy and cholesterol absorption. Current Atherosclerosis Reports, 6(2), 89-93. http://dx.doi.org/10.1007/s11883-004-0095-5

Mohammadi, A., Abbasi-Oshaghi, E., Noori-Sorkhani, A., Oubari, F., Kia, R., \& Rezaei, A. (2012). Effect of Opium on Lipid Profile and Expression of Liver X Receptor Alpha (LXR $\alpha)$ in Normolipidemic Mouse. Food and Nutrition Sciences, 3(2), 249-254. http://dx.doi.org/10.4236/fns.2012.32036

Mohammed, K., Ali, K. M., Narayan, V., \& Tandon, N. (2010). Diabetes \& coronary heart disease: Current perspectives. Indian J Med Res, 132, 584-597.

Pellizzon, M. A., Billheimer, J. T., Bloedon, L. T., Philippe, R. D., Szapary, O., \& Rader, D. J. (2007). Flaxseed Reduces Plasma Cholesterol Levels in Hypercholesterolemic Mouse Models. Journal of the American College of Nutrition, 26(1), 66-75. http://dx.doi.org/10.1080/07315724.2007.10719587

Vafa, M., Mohammadi, F., Shidfar, F., Sormaghi, M., Heidari, I., \& Golestan, B. (2012). Effects of Cinnamon Consumption on Glycemic Status, Lipid Profle and BodyComposition in Type 2. J Prev Med, 3, 531-536.

Zhoa, C., \& Dahlman-Wright, K. (2010). Liver X receptor in cholesterol metabolism. J Endocrinol, 204(3), 233-240. http://dx.doi.org/10.1677/JOE-09-0271

\section{Copyrights}

Copyright for this article is retained by the author(s), with first publication rights granted to the journal.

This is an open-access article distributed under the terms and conditions of the Creative Commons Attribution license (http://creativecommons.org/licenses/by/3.0/). 